\title{
Flood Water Crossing: Laboratory Model Investigations for Water Velocity Reductions
}

\author{
N. Kasnon ${ }^{1}$, A.N. Abdul Ghani ${ }^{2, a}$ \\ ${ }^{1,2}$ School of Housing, Building and Planning, Universiti Sains Malaysia, 11800, Penang, Malaysia
}

\begin{abstract}
The occurrence of floods may give a negative impact towards road traffic in terms of difficulties in mobilizing traffic as well as causing damage to the vehicles, which later cause them to be stuck in the traffic and trigger traffic problems. The high velocity of water flows occur when there is no existence of objects capable of diffusing the water velocity on the road surface. The shape, orientation and size of the object to be placed beside the road as a diffuser are important for the effective flow attenuation of water. In order to investigate the water flow, a laboratory experiment was set up and models were constructed to study the flow velocity reduction. The velocity of water before and after passing through the diffuser objects was investigated. This paper focuses on laboratory experiments to determine the flow velocity of the water using sensors before and after passing through two best diffuser objects chosen from a previous flow pattern experiment.
\end{abstract}

\section{Introduction}

Flooded roads happen when the amount of water on the road is more than what the road drainage can cope with. Roads that have been flooded must be carefully managed. To do this, road closures, load restrictions and traffic management may be implemented to protect road users and road assets, and balance the access for the community and industry.

In a general flooding scenario, water levels rise causing the areas neighbouring water bodies and some road segments in these areas to be flooded. Two aspects of flooding are of interest to researchers; first, when the water body reaches a water level higher than normal causing water to flow to the surrounding areas and second, when the flowing water interacts with roads, covering road segments [1]. The primary effects of flooding include loss of life, damage to buildings and other structures, roadways and canals. Damage to roads and transport infrastructure may make it difficult to mobilise aid to those affected or to provide emergency health treatment.

The detrimental impact of flooding on roadways would not be so easily determined [2]. There are many impacts from flooding. Exceptional rainfall, a road being in a low lying area or changes in 'run off' water from nearby land are some of the reasons why a road might flood even though the drainage system is in good working order [3]. Flooding can be very dangerous and of fast-flowing water could knock and sweep off people. Floodwater can seriously disrupt public and personal transport by cutting off roads and railway lines, as well as communication links when telephone lines are damaged. Floods can damage roadway and disrupt normal drainage systems in cities, and sewage spills are common. Flooding not only disrupts many people's lives each year, but it frequently creates personal tragedies

${ }^{\text {a }}$ Corresponding author : anaser@usm.my 
when people are swept away and drowned. Water velocities tend to be high in flood crossings. The high velocity of flood waters that cross roadway allows the water to cause more difficulties in mobilisation, damaging vehicles and endangering people's lives.

A laboratory model capable of flexibly measuring the water velocity is required. One method that can be developed to study water velocity is using a velocity sensor placed in a flume. This paper investigated the flood water velocity before and after passing through two types of diffuser objects that have been selected from previous preliminary studies on floods.

\section{Methodologies}

The methodology used in this study was a lab experiment. The experiment was conducted in a laboratory using laboratory equipment, and the data was collected through a computer and calculations. The apparatus used in this experiment are water flume, sensor, computer connected to sensors, water pump, water container, two types of $3 \mathrm{D}$ water diffuser and a data logger. The apparatus were set up as in Figure 1 and Figure 2, showing the test configuration.

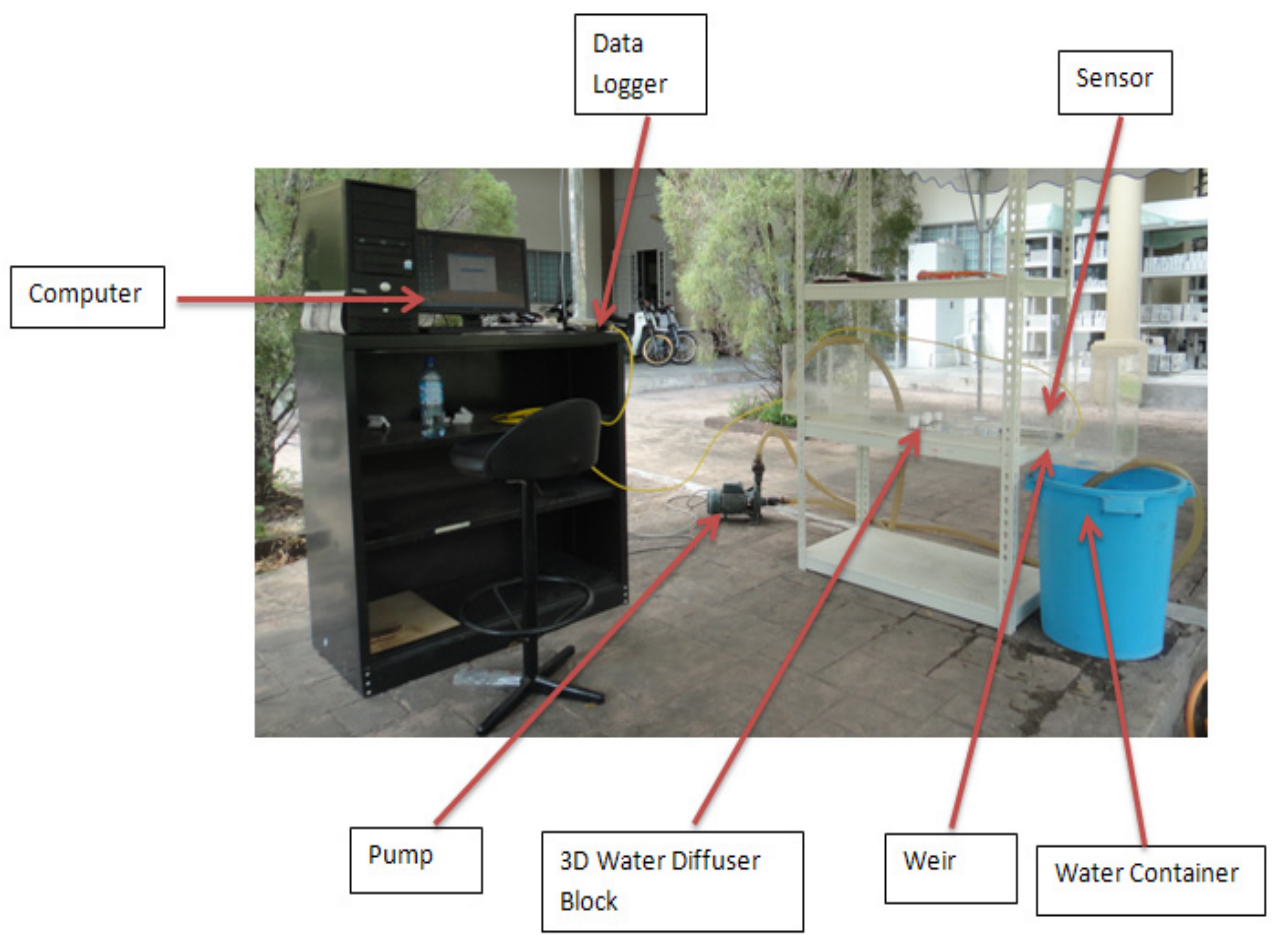

Fig 1: Experiment set up

The experiment was set up as Figure 1 in which water was pumped to circulate within the systems. The water was filtered through the small holes so as to maintain the speed and a continuous flow passing through the block diffusers, while the sensors detected the velocity of the water flowing before and after the passing. The two 3D diffusing blocks varied with the shape and orientation and were tested separately. The readings were transferred to the computer through the data logger. The water flows into the container through the hole at the end of the box. The flow rates $(Q)$ in $1 / \mathrm{s}$ were detected by the sensor and the reading transferred through the data logger to the computer. The values of velocity (V) were calculated and readings were compared at every four points on the road scale. This experiment maintained the scale of 1:20 and it corresponded to a $3 \mathrm{~m}$ width two lane road (i.e. road=3m@15cm, road shoulder=1m@5cm and diffuser model=1m@,5cm). 


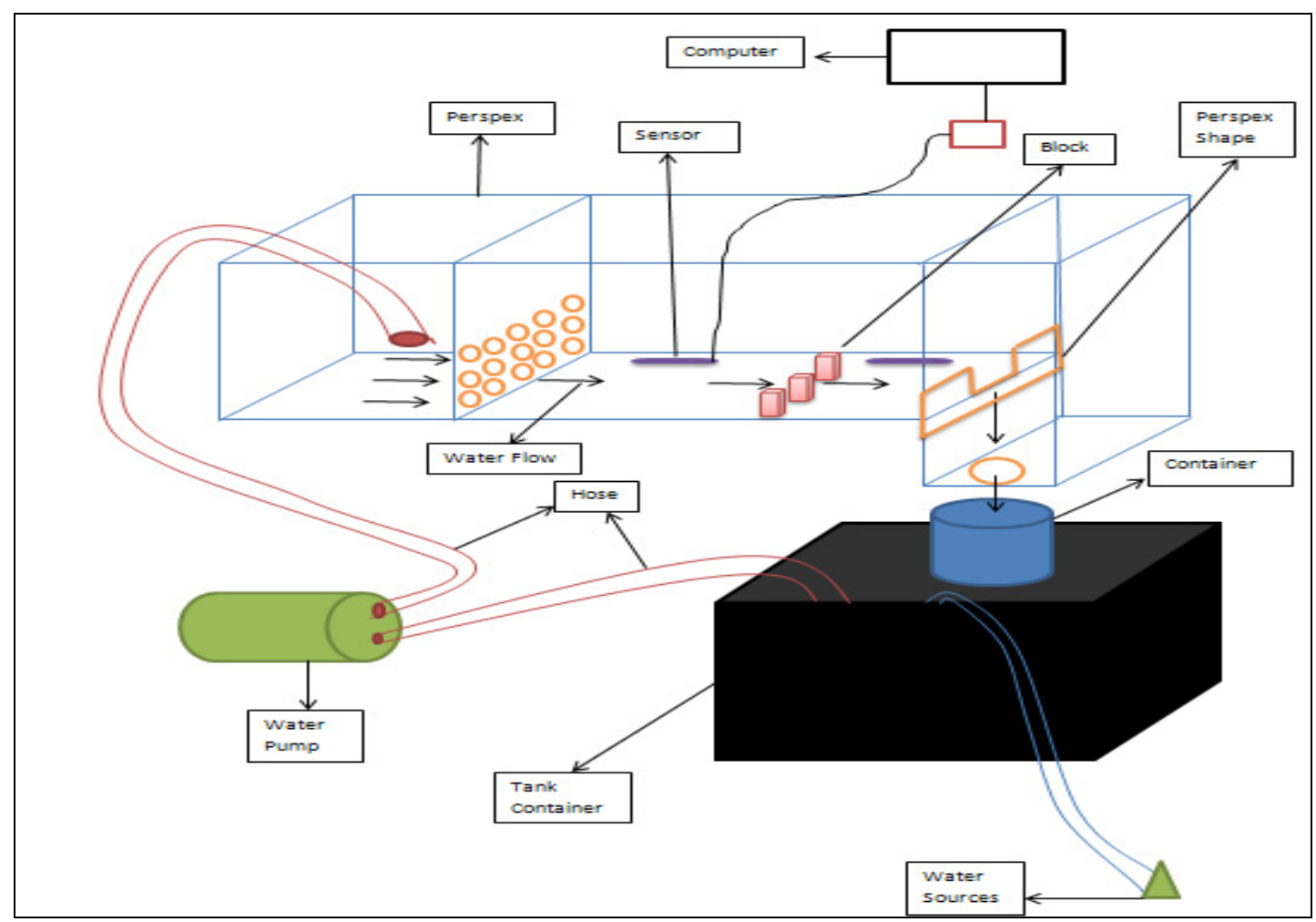

Fig 2: Test configuration

\subsection{Pilot test}

Before doing the experiment for actual calculations and data collection, preliminary tests were done. The purpose of the tests was to collect the preliminary data only for preparation of sensor calibrating so that the sensor is calibrated and will be able to detect the water flow and works satisfactorily. This will help to ensure that the experiment can be conducted smoothly and the sensor functions well to produce a high quality result.

\subsubsection{Weir Shape}

The preliminary test was also conducted for the preparation of the sensor calibration by using a weir that was placed at the end of the flume. This is because the sensor will be calibrated with a suitable height of water which is not too high or low. Five types of weir were tested and Figure 3 shows the weir chosen and the position of the weir in the experiment.

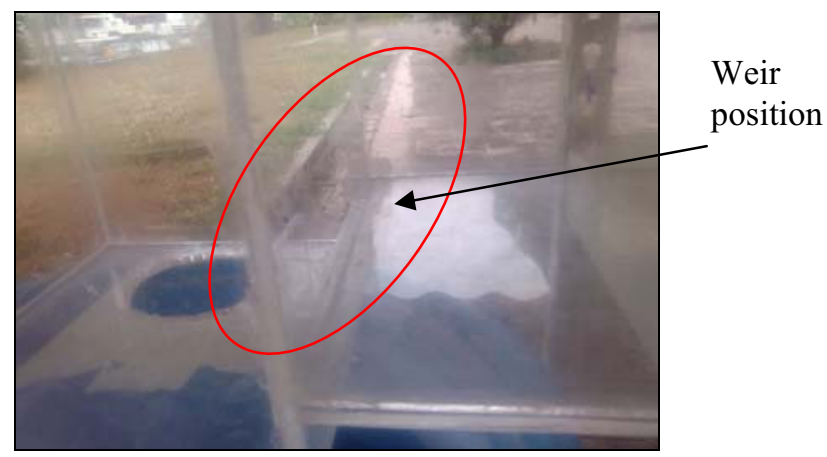

Fig 3: Weir shape position 


\section{Results and Discussions}

The sensors were placed at the beginning, middle and end of the road cross section to study the variation of flow after it had passed through the diffusers. Velocity (V) was recorded and the readings were compared at every four locations of the road scales. Figure 4 shows the specification measurements of the model and the point where the water velocity was measured. The results that came out from the sensor reading were the flow rate of the water, Q. The velocity of the water was calculated by the formula: $\mathrm{V}=\mathrm{Q} / \mathrm{A}$

Which,

$\mathrm{V}=$ velocity of water

$\mathrm{Q}=$ water flow rate

$\mathrm{A}=$ Area

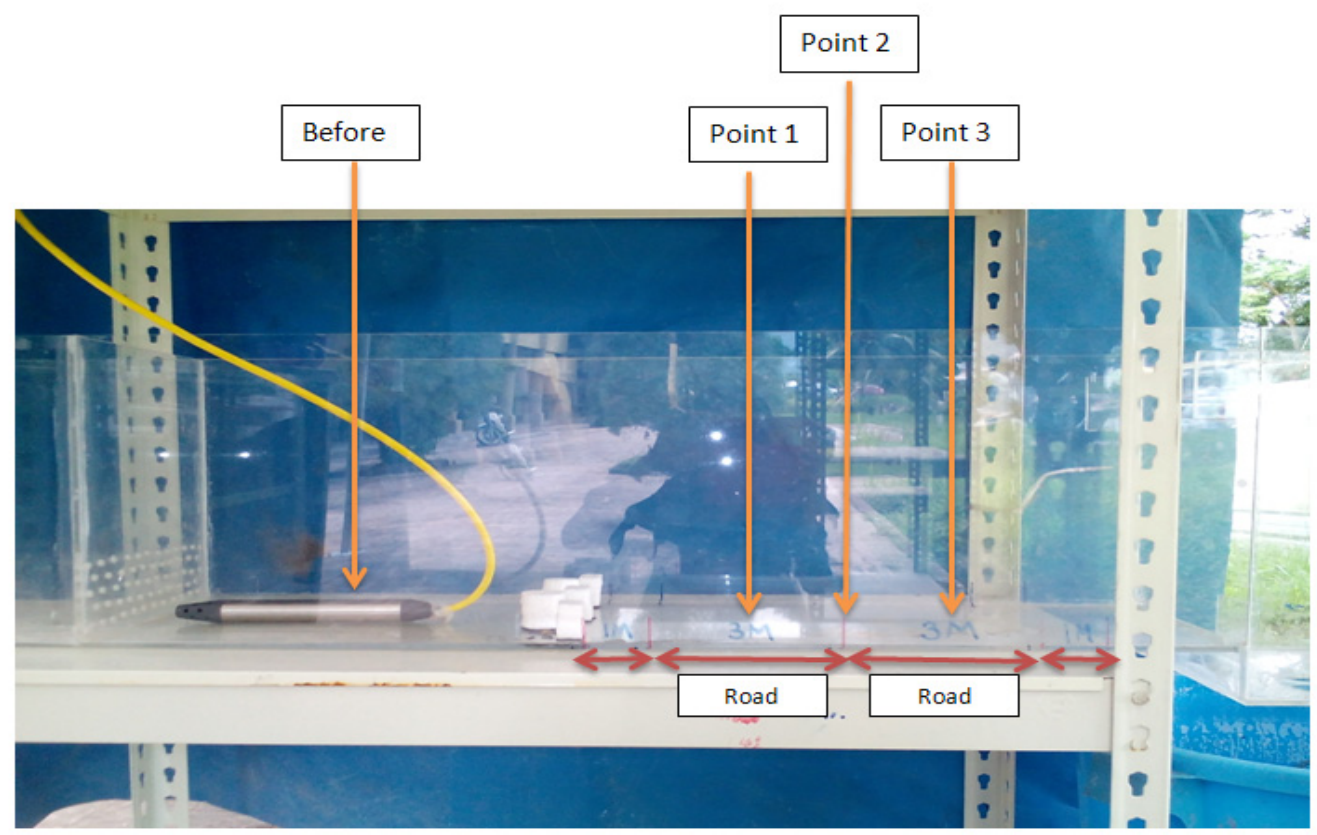

Fig 4: Specification measurement

Table 1: Water velocity for diffuser object 1

\begin{tabular}{|c|c|c|c|c|}
\hline Reading & Before $(\mathrm{cm} / \mathrm{s})$ & After $(1)(\mathrm{cm} / \mathrm{s})$ & After $(2)(\mathrm{cm} / \mathrm{s})$ & After $(3)(\mathrm{cm} / \mathrm{s})$ \\
\hline 1 & 5.15 & 2.35 & 5.15 & 2.92 \\
\hline 2 & 3.62 & 3.08 & 4.04 & 6.00 \\
\hline 3 & 5.46 & 3.73 & 4.04 & 5.85 \\
\hline 4 & 4.35 & 3.88 & 4.81 & 5.85 \\
\hline 5 & 4.50 & 4.04 & 4.65 & 6.54 \\
\hline 6 & 6.19 & 4.19 & 4.81 & 6.73 \\
\hline 7 & 5.31 & 4.81 & 5.85 & 7.12 \\
\hline 8 & 5.31 & 4.65 & 5.00 & 7.12 \\
\hline 9 & 5.85 & 4.50 & 6.00 & 7.31 \\
\hline 10 & 5.46 & 4.65 & 5.31 & 7.70 \\
\hline
\end{tabular}


Table 2: Water velocity for diffuser object 2

\begin{tabular}{|c|c|c|c|c|}
\hline Reading & Before(cm/s) & $\begin{array}{c}\text { After(1)(2.5cm) } \\
(\mathbf{c m} / \mathbf{s})\end{array}$ & $\begin{array}{c}\text { After(2)(4cm) } \\
(\mathbf{c m} / \mathbf{s})\end{array}$ & $\begin{array}{c}\text { After(3)(5.5cm) } \\
(\mathbf{c m} / \mathbf{s})\end{array}$ \\
\hline 1 & 5.85 & 2.35 & 4.04 & 5.65 \\
\hline 2 & 6.54 & 4.04 & 4.50 & 5.46 \\
\hline 3 & 5.85 & 3.62 & 4.50 & 6.19 \\
\hline 4 & 5.46 & 3.88 & 4.19 & 5.15 \\
\hline 5 & 5.85 & 3.62 & 3.73 & 4.65 \\
\hline 6 & 5.85 & 3.35 & 4.35 & 5.85 \\
\hline 7 & 5.85 & 3.46 & 5.15 & 5.65 \\
\hline 8 & 6.54 & 4.19 & 4.65 & 6.35 \\
\hline 9 & 6.54 & 4.19 & 5.46 & 7.12 \\
\hline 10 & 7.31 & 6.19 & 7.50 & 8.96 \\
\hline
\end{tabular}

Table 3 shows the average of the water velocity from the results above and the graphic patterns of the average are shows in Figures 5 and 6.

Table 3: Average of water velocity

\begin{tabular}{|c|c|c|c|c|}
\hline Object & Before & $\begin{array}{c}\text { After }(1) \\
(2.5 \mathrm{~cm})(\mathrm{cm} / \mathrm{s})\end{array}$ & $\begin{array}{c}\text { After(2) } \\
(4 \mathrm{~cm})(\mathrm{cm} / \mathrm{s})\end{array}$ & $\begin{array}{c}\text { After }(3) \\
(5.5 \mathrm{~cm})(\mathrm{cm} / \mathrm{s})\end{array}$ \\
\hline 1 & 5.12 & 3.98 & 4.96 & 6.31 \\
\hline 2 & 6.16 & 3.89 & 4.81 & 6.10 \\
\hline
\end{tabular}

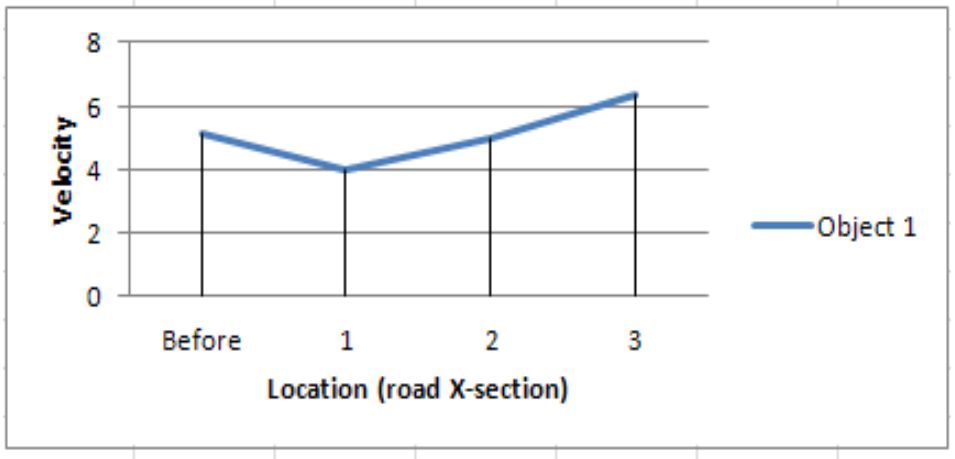

Fig 5: Graphic pattern of diffuser object 1

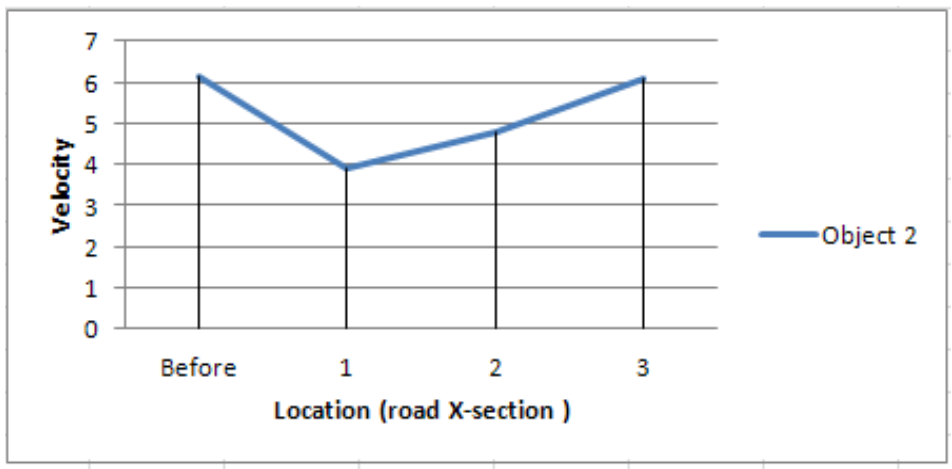

Fig 6: Graphic pattern of diffuser object 2 
From the average above, the reduction percent of the water velocity at every point was determined. This can be seen up until the point of the water velocity reduction after the water flowed through the diffuser blocks. Table 4 shows the percent of the velocity reduction.

Table 4: Water velocity reduction

\begin{tabular}{|c|c|c|c|c|}
\hline Object & Before $(\%)$ & $\begin{array}{c}\text { Point } 1 \\
(1)(2.5 \mathrm{~cm})(\%)\end{array}$ & $\begin{array}{c}\text { Point } 2 \\
(4 \mathrm{~cm})(\%)\end{array}$ & $\begin{array}{c}\text { Point 3) } \\
(5.5 \mathrm{~cm})(\%)\end{array}$ \\
\hline 1 & $100 \%$ & $78 \%$ & $97 \%$ & $123 \%$ \\
\hline 2 & $100 \%$ & $63 \%$ & $77 \%$ & $97 \%$ \\
\hline
\end{tabular}

From the average results and the percent reduction of the water flow velocity, it can be seen that the water velocities were reduced after the water had flowed through both types of diffuser objects. This means that the velocity of the water becomes slow after flowing through the diffuser object at point 1 . However the water velocity increases a bit after point 1 . Figure 7 illustrates the velocity reduction effects.

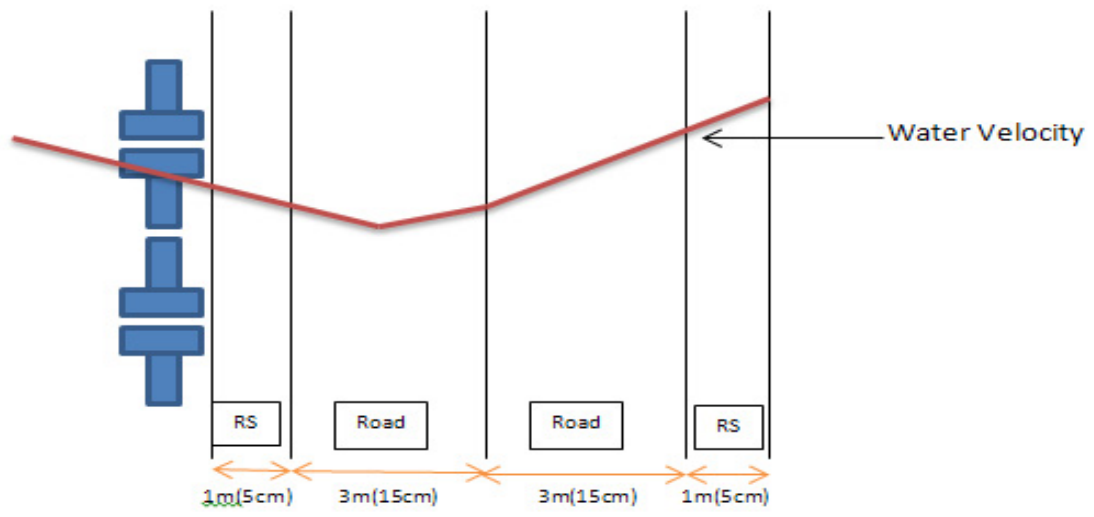

Fig 7: Water velocity reduction - object 1

Figure 8 shows the velocity reduction effect of diffuser object 2 . Similar results were recorded as object 1 but the water velocity at point 3 or beyond the road section were still lower than the original velocity. This means that even though the water velocity regained its speed toward the end of the road section, it was still below the original speed i.e. before it was diffused. The ability of object 2 to maintain the velocity reduction until the flow was beyond the road section makes it a more suitable object for further investigations.

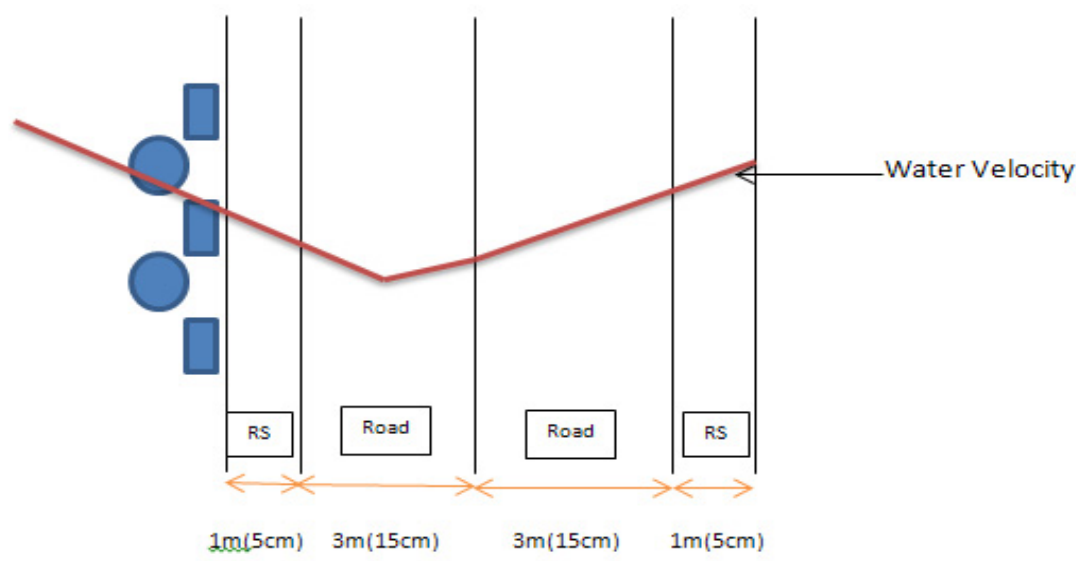

Fig 8: Water flow pattern of diffuser object 2 


\section{Conclusion}

The laboratory model investigation refines and confirms the findings from previous 2-D flow pattern investigations [4]. Both tested objects gave the impact of velocity reduction as expected. However, the better diffuser object for water velocity reduction is diffuser object 2 . This is because the water velocity, after passing through the diffuser object, is maintained until it crosses the road. This object shape and orientation as well as it geometric placement can be further investigated to produce more alternatives in terms of flood crossings and site conditions.

\section{Acknowledgement}

The authors would like to acknowledge financial support for this study by research grant no. 203/PPBGN/6711257 provided by USM/MOE Malaysia.

\section{References}

1. Hubo Cai, Ph.D. William Rasdorf, Ph.D., P.E., F.ASCE and Chris Tilley, 2007, Approach to Determine Extent and Depth of Highway Flooding, Journal of Infrastructure System.

2. Zhongjie Zhang1; Zhong Wu2; Mark Martinez3; and Kevin Gaspard4, May 2008, Pavement Structures Damage Caused by Hurricane Katrina Flooding, Journal of Geotechnical and Geoenvironmental Engineering (C) ASCE.

3. Mc Cormack, 2012, Kentucky Transportation Center.

4. A.N. Abdul Ghani and N. Kasnon (2014). Effect of Flood Water Diffuser on Flow Pattern of Water during Road Crossing. MATEC Web of Conferences 1006006 (2014). DOI: $10.1051 /$ matecconf/20141006006 